\title{
Gamificación en la docencia universitaria en la asignatura de Prótesis Estomatológica I
}

\author{
EMILIO JIMÉNEZ-CASTELLANOS BALLESTEROS \\ Universidad de Sevilla \\ Facultad de Odontología \\ Departamento de Estomatología \\ ejcb@us.es \\ ORCID: https://orcid.org/0000-0002-4275-8288 \\ D.O.I.: http://dx.doi.org/10.12795/JDU.2018.i01.19 \\ Pp.: 336-355
}

\section{Resumen}

El CMD (Ciclo de Mejora Docente) que hemos desarrollado en el presente curso académico 2017-18, se ha llevado a cabo en la asignatura de Prótesis Estomatológica I, básicamente consiste en la introducción de la "Gamificación" (a través de KAHOOT) en la docencia teórica de la citada asignatura de segundo curso del Grado de Odontología.

La experiencia ha sido muy gratificante, permitiendo una dinamización de la clase teórica que me era impensable conseguir al inicio de la actividad, es preciso destacar, que dicha actividad es imposible de llevar a cabo sin la participación activa de los alumnos, lo que supone un hándicap dada la habitual pasividad de los mismos en su trayectoria discente tanto a nivel de estudios preuniversitarios, como universitarios del Grado. Es mi intención seguir esta trayectoria en cursos sucesivos, planteado el reto de estimular a los alumnos para conseguir una mayor participación en su aprendizaje. 
Palabras Claves: Prótesis Estomatológica I. Grado en Odontología. Docencia Universitaria. Innovación docente universitaria. Gamificación.

\section{Breve descripción del contexto}

La asignatura de Prótesis Estomatológica I se imparte en el segundo semestre del segundo curso del Grado en Odontología. Tiene una carga lectiva de 6 créditos totales, 3 teóricos y 3 prácticos de laboratorio. La asignatura se imparte en dos grupos de teoría y dos de prácticas, siendo responsable en el presente curso académico del grupo B, con un total de 53 alumnos matriculados. El CMD se aplicó en los contenidos teóricos de la materia. La asistencia a las prácticas de laboratorio es obligatoria (no se admiten más de dos faltas durante el curso), no así la asistencia a las clases teóricas, lo que ha supuesto que el número real de alumnos asistentes a dicha actividad oscilara entre 11 y 30, disminuyendo la asistencia progresivamente a lo largo del curso debido a distintas circunstancias, entre las que podemos destacar: el hecho de que muchos de los alumnos no tienen su residencia en Sevilla y al impartirse las clases a primera hora de la mañana de los lunes (8,00 a 10,00 horas) no acuden, otra razón aducida se debe al hecho de que en el segundo curso del Grado se concentran otras asignaturas (10 en total, incluida la Prótesis) con un alto volumen de contenidos que sobrecarga el trabajo de los alumnos, debemos mencionar también la necesaria participación y trabajo autónomo del alumno en el CMD de manera activa, lo que dada la "costumbre pasiva" de los alumnos en otras materias haya contribuido a la falta de disposición de muchos de ellos y por último mencionar que al acercarse la época de exámenes finales, los alumnos tienden a ausentarse de clase.

Finalmente mencionar que el aula de impartición tiene una capacidad para 49 alumnos, dotada con todos los medios técnicos necesarios para llevar a cabo la actividad. 


\section{Diseño previo del ciclo de Mejora Docente}

Mapa de contenidos y problemas que describan los aprendizajes deseables y los núcleos de trabajo en el aula

El mapa de contenidos de la asignatura se refleja a continuación:

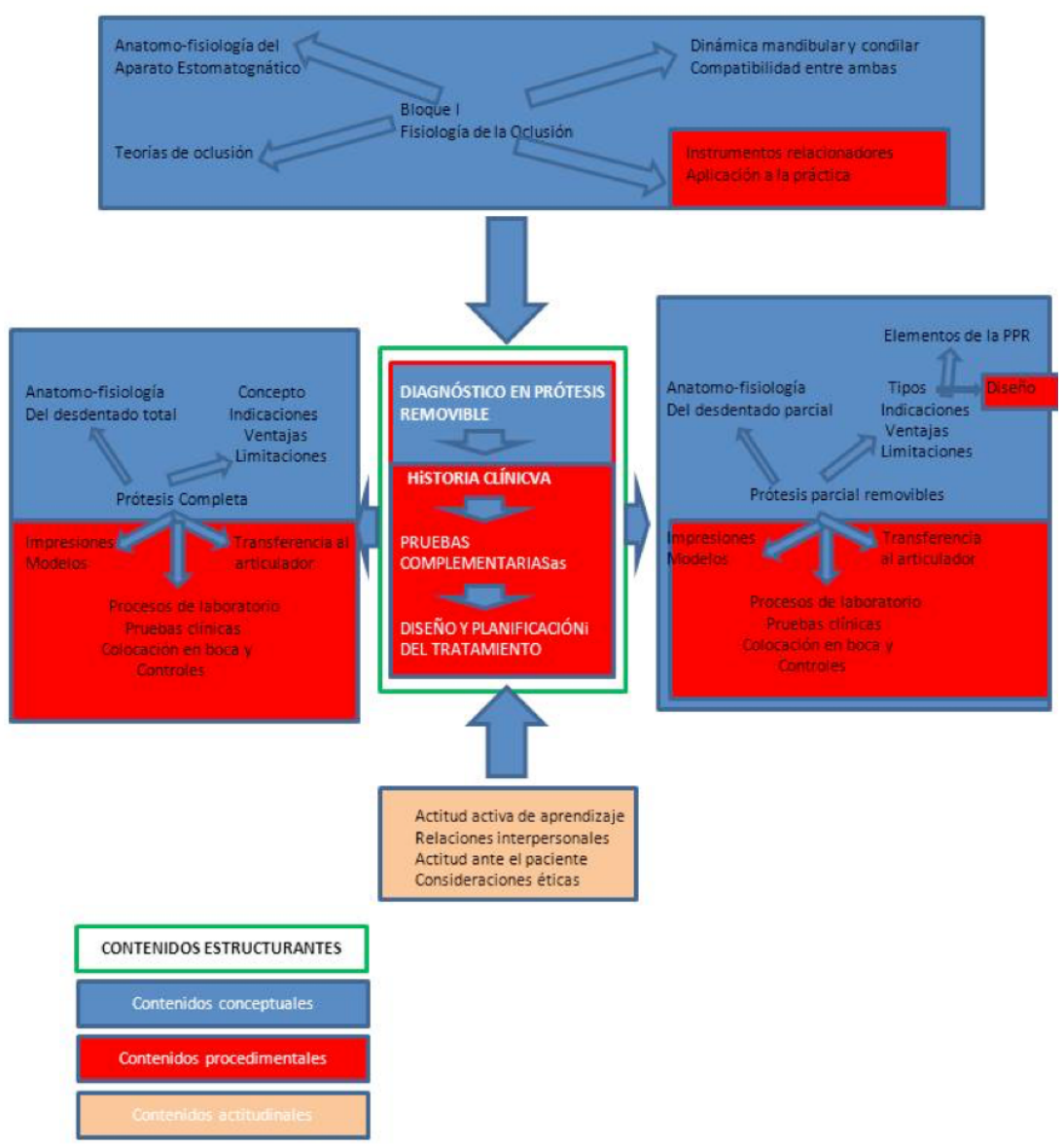

Figura 1. Contenidos de la asignatura

La asignatura se puede compendiar en tres grandes bloques temáticos:

Jornadas de Formación e Innovación Docente del Profesorado | № 1 (2018)

(c) $€$ Esta obra se distribuye con la licencia Creative Commons Reconocimiento-NoComercial-SinObraDerivada $\quad 4.0$ Internacional (CC BY-NC-ND 4.0.) 
1. ¿Cuál es la forma y función del Aparato Estomatognático y su aplicación al diagnóstico en Prótesis Estomatológica? (Contenidos cuadro superior)

2. ¿Cuáles son los procedimientos para el diagnóstico y tratamiento del desdentado total mediante prótesis removible? (Contenidos cuadro izquierdo)

3. ¿Cuáles son los procedimientos para el diagnóstico y tratamiento del desdentado parcial mediante prótesis removible? (Contenidos cuadro derecho)

Los contenidos estructurantes u organizadores se reflejan en el centro del mapa y hacen referencia a la realización de un correcto diagnóstico y plan de tratamiento en Prótesis removible estomatológica.

Estos contenidos estructurales incardinan el conocimiento de la anatomo-fisiología normal del Aparato Estomatognático para sentar las bases de las estructuras y funciones a rehabilitar en el paciente desdentado Total mediante prótesis completa mucosoportada y en el paciente desdentado parcial mediante prótesis parcial removible dento, dento-muco o mucosoportada.

A su vez en cada uno de los sub-apartados o bloques se recogen los contenidos estructurantes de los mismos, (parte superior fisiología de la oclusión, parte izquierda prótesis completa parte derecha prótesis parcial removible).

Por último, se han diferenciado en colores los contenidos conceptuales (a trabajar eminentemente en las clases teóricas) de los procedimentales (clases prácticas) y actitudinales (ambas). 


\section{Modelo metodológico posible y secuencia de actividades programadas, partiendo de los problemas seleccionados}

Para trabajar las preguntas problemas, se han dividido por temas, de manera que se trabajarán tres temas en cada 2 horas de clase semanal, mediante la gamificación he creado 12 "Kahoot" con un total de 10 preguntas cada uno (con una media de tres preguntas por tema) en dos formatos diferentes, en primer lugar en el formato "Survey", se dan cuatro respuestas posibles a la pregunta formulada, optando el alumno por la opción que le parezca más oportuna, pero sin apuntar la respuesta correcta, tan solo se refleja el porcentaje de alumnos que elije cada respuesta de las cuatro posibles.

Ejemplo de pregunta del tema 10:

- ¿Cuál es la finalidad del arco de transferencia en el dentado?

- Respuestas:

- Transferir relación del modelo superior respecto al cráneo

- Transferir la distancia del modelo respecto al eje de giro

- Transferir la inclinación del Plano de oclusión

- Todas las anteriores

El siguiente tipo es en formato "Quiz" de similares características pero aportando la solución final y la puntuación de los alumnos que tuvieran un mayor número de aciertos en el tiempo estipulado de respuesta. Este último formato me permite además recoger, una vez finalizado "el juego", el porcentaje total de aciertos a las preguntas formuladas, así como la opinión "subjetiva" de los alumnos sobre su nivel de aprendizaje.

Jornadas de Formación e Innovación Docente del Profesorado | № 1 (2018) Esta obra se distribuye con la licencia Creative Commons 


\section{Secuencia de actividades}

El primer día de clase de impartición de la asignatura, dedicada a explicar los objetivos, competencias, programa teórico y práctico, sistemas y criterios de evaluación, etc., al final de la misma, les puse dos pequeños videos de dos secuencias de películas muy conocidas. El primero de ellos era la secuencia de la película de Indiana Jones (en Busca del Arca perdida) en la que aparece Harrison Ford dando una clase de tipo "Magistral" con participación pasiva de los alumnos, en la segunda, El Club de los poetas muertos, Robin Williams da una clase con una participación y protagonismo de los alumnos. Tras el visionado de los mismos les pregunté a los alumnos ¿quiénes creían que habían aprendido más? A lo que mayoritariamente respondieron que los alumnos del segundo video. Seguidamente les pregunté ¿Qué tipo de Profesor querían que yo interpretara?, a lo que respondieron unánimemente que el del segundo modelo.

Estos videos me sirvieron para obtener el compromiso de los alumnos para participar activamente en el ciclo de mejora, de manera que:

El primer día del ciclo de mejora pasaré a los alumnos un cuestionario con las "Preguntas Problema" que servirá, una vez analizado para establecer una escalera inicial de aprendizaje.

La semana antes de la clase teórica, los alumnos tienen a su disposición los apuntes completos de cada uno de los temas a trabajar y el compromiso de leerlos y anotar las dudas que pudieran surgir.

Los primeros 5 minutos de clase los dedicamos a hacer grupos de 4-5 alumnos y discutir entre ellos las dudas del tema. A continuación los alumnos van exponiendo sus dudas a las cuales solicito a los propios alumnos que crean conocer la respuesta, que la aclaren a sus compañeros, siendo mi misión la de moderar el debate y reconducirlo, 
apoyando además con imágenes de ordenador en el caso que fuera necesario y según los temas con modelos reales de prótesis o sus distintas fases así como instrumentos diagnósticos que le sirvan al alumno para familiarizarse, todavía más, con la realidad profesional a la que capacita el Grado en Odontología.

Esta primera fase tiene como finalidad detectar cuáles son las principales dudas de los alumnos y si se trata de cuestiones de primer o segundo índole.

En la segunda fase que relataré a continuación, soy yo quién formula las preguntas, lo que me permite, a través de las preguntas seleccionadas, hacer hincapié en los contenidos estructurales o en aquellos secundarios que por experiencia de otros años cuesta más al alumno de aprender.

Una vez finalizadas todas las dudas, procedo a pasar el primer Kahoot en formato "Survey", en dicho juego planteo 10 preguntas de los temas a tratar. Tras cada pregunta (al no presentar la respuesta correcta este formato, sino solo el porcentaje de alumnos que eligen cada respuesta) pido a los alumnos que defiendan su respuesta elegida y discutimos y razonamos cuál es la respuesta correcta.

Al final de la clase pasaremos el segundo Kahoot, pero en formato "Quiz" que sí da la respuesta correcta tras el tiempo estipulado y con puntuación a los alumnos que alcancen mayor número de respuestas acertadas, lo que estimula a los alumnos a esforzarse en aplicar lo aprendido sirviendo de refuerzo del aprendizaje.

Por último, y una vez evaluado por los alumnos el Kahoot, recojo en una tabla Excel, el porcentaje de aciertos y la opinión subjetiva del alumnos sobre la utilidad para el aprendizaje del Kahoot empleado y en definitiva del método de aprendizaje.

Para analizar el proceso de aprendizaje además del análisis inicial y final del cuestionario de los casos problema a trabajar, me propongo "pasar lista" para poder registrar en la evaluación teórica final si hay diferencia en las 
calificaciones de los alumnos que asisten a clase con los que no y si ha mejorado la tasa de rendimiento con respecto a cursos anteriores.

Esta metodología de aprendizaje se complementa con las clases prácticas en las que los alumnos tienen que aplicar parte de los conocimientos teóricos adquiridos junto a sus habilidades prácticas.

\section{Cronograma}

Cada actividad teórico o práctica tiene una duración de dos horas.

19-3-18: Actividad teórica: Cuestionario inicial de preguntas problema y Resolución de dudas y Kahoot correspondientes a los temas 16,17,18

23-3-18 Actividad práctica: Trabajo de habilidades con planchas base y rodillos articulares

2-4-18: Actividad teórica: Resolución de dudas y Kahoot correspondientes a los temas 19,20 y 21

6-4-18 Actividad práctica: Trabajo de habilidades con planchas base y rodillos articulares

9-4-18: Actividad teórica: Resolución de dudas y Kahoot correspondientes a los temas 22,23 y 24

13-4-18 Actividad práctica: Trabajo de habilidades con transferencia del modelo superior al articulador

23-4-18 Actividad teórica: Resolución de dudas y Kahoot correspondientes a los temas 25,26 y 27

27-4-18 Actividad práctica: Trabajo de habilidades con transferencia del modelo superior al articulador

30-4-18 Actividad teórica: Resolución de dudas y Kahoot correspondientes a los temas 28,29 y 30

4-5-18 Actividad práctica: Trabajo de habilidades libre por parte del alumno (supervisado por el Profesor) para entrenar aquellas que considere que tiene menos desarrolladas de todas las trabajadas a lo largo del curso.

7-5-18 Actividad teórica: Resolución de dudas y Kahoot correspondientes a los temas 31,32,33 
11-5-18 Actividad práctica: Trabajo de habilidades libre por parte del alumno (supervisado por el Profesor) para entrenar aquellas que considere que tiene menos desarrolladas de todas las trabajadas a lo largo del curso.

14-5-18 Actividad teórica: Resolución de dudas y Kahoot correspondientes a los temas 35,36,37

18-5-18 Actividad práctica: Trabajo de habilidades libre por parte del alumno (supervisado por el Profesor) para entrenar aquellas que considere que tiene menos desarrolladas de todas las trabajadas a lo largo del curso.

21-5-18 Actividad teórica: Resolución de dudas y Kahoot correspondientes a los temas 34 y 38

25-5-18 Actividad práctica: Trabajo de habilidades libre por parte del alumno (supervisado por el Profesor) para entrenar aquellas que considere que tiene menos desarrolladas de todas las trabajadas a lo largo del curso.

28-5-18 Actividad teórica: Cuestionario final de preguntas problema

1-6-18 Actividad práctica: Trabajo de habilidades libre por parte del alumno (supervisado por el Profesor) para entrenar aquellas que considere que tiene menos desarrolladas de todas las trabajadas a lo largo del curso.

8-6-18 Actividad práctica: Evaluación de habilidades mediante examen práctico sobre las habilidades trabajadas a lo largo del curso.

15-6-18 Evaluación teórica final de la asignatura

Cuestionario inicial-final para hacer un seguimiento de la evolución de los estudiantes en relación con los problemas clave

Las preguntas "problema” generales, con una primera aproximación a escala de aprendizaje a expensas de las contestaciones de los alumnos serían las siguientes:

1. ¿Por qué el "Diagnóstico en Prótesis removible" aparece como eje central de la asignatura? (Se refiere al mapa de contenidos que se incluirá en el cuestionario) 
Respuestas de menor a mayor:

a) No lo sé

b) Porque se relaciona con el resto de los contenidos

c) Porque es fundamental para saber la situación del paciente

d) Porque un correcto diagnóstico permitirá establecer una correcta indicación del Plan de tratamiento

2. ¿Cuál es la utilidad práctica en prótesis de conocer en profundidad la dinámica condilar y mandibular?

a) no lo sé

b) no tiene ninguna utilidad

c) Para mejorar el tratamiento de los pacientes

d) Para conseguir prótesis con una anatomía oclusal compatible con la dinámica condilar del paciente

3. Por qué es conveniente utilizar los articuladores semiajustables?

a) No sirven para nada

b) Para hacer prótesis

c) Para conseguir mejores resultados en nuestras prótesis

d) Para conseguir una correcta oclusión en las prótesis y que sean funcionales

4. ¿De qué depende la retención y estabilidad de una prótesis completa?

a) De lo bien hecha que esté

b) De los rebordes alveolares residuales del paciente

c) De los rebordes alveolares residuales del paciente y del control muscular

d) De los rebordes alveolares residuales del paciente y del control muscular de la saliva y de la oclusión

5. ¿Por qué diseño una oclusión balanceada bilateral en prótesis completa?

a) no lo se

b) Porque es la más fácil de hacer

c) Porque mejora la estabilidad de la prótesis

Jornadas de Formación e Innovación Docente del Profesorado | № 1 (2018) Esta obra se distribuye con la licencia Creative Commons Reconocimiento-NoComercial-SinObraDerivada 
d) Porque contribuye a mejorar la retención y estabilidad de la prótesis

6. ¿Cómo sé el tamaño y forma de dientes que debo indicar en un paciente desdentado total?

a) no lo se

b) Mirando fotos antiguas del paciente

c) Por los gustos del paciente

d) Por una serie de referencias faciales como son el labio superior en reposo, la línea de sonrisa y la línea de caninos.

7. ¿De qué dependerá que en un paciente desdentado parcial haga una prótesis esquelética o una prótesis parcial de resina?

a) No lo sé

b) De las preferencias y economía del paciente

c) Del diagnóstico

d) Del diagnóstico particularmente del número, disposición y superficie periodontal de los dientes remanentes

8. ¿Qué diferencia fundamental existe entre los tipos de prótesis de la pregunta anterior?

a) No lo sé

b) el precio

c) los materiales de confección

d) La vía de transmisión de las fuerzas oclusales a través del diente o de la mucosa

\section{Aplicación del CMD}

\section{Relato resumido de las sesiones}

Las sesiones de trabajo se han llevado a cabo como estaban diseñadas, es decir: a principio de la clase, dejamos 5 minutos para que los alumnos, solos o en grupos apuntaran todas las dudas referentes a los temas a tratar, 
seguidamente se realiza una puesta en común en la que los alumnos iban planteando sus dudas, siendo mi labor la de estimular y conducir la discusión para que fueran los propios compañeros los que contestaran las dudas propuestas, una vez resueltas, se procedió a realizar la primera fase de la gamificación, con los cuestionarios realizados en Kahoot con la modalidad "Survey", la cual da pie a establecer a su vez una discusión en el auditorio sobre cuál podría ser la respuesta correcta, ya que dicha aplicación tan solo señala el porcentaje de alumnos que han consignado cada una de las cuatros posibles respuestas. Es preciso destacar que las preguntas planteadas estaban especialmente diseñadas para poder conectar a su vez con otras cuestiones clave y permitir al mismo tiempo una visión integradora de la asignatura. Por último, bien en la misma sesión, o en la mayoría de los casos en la sesión siguiente, se volvía a realizar la gamificación, pero esta vez con el modelo "Quiz" (que señala la respuesta correcta una vez participados los alumnos) junto a una escala de puntuación de los alumnos acertantes, lo que servía de repaso de los temas tratados en la sesión anterior. (Es preciso aclarar que las preguntas de ambos Kahoot en sus dos modalidades eran siempre las mismas, pero cambiadas de orden, tanto las preguntas como las respuestas, para evitar la "Memoria fotográfica").

En lo referente al clima de trabajo, de un lado he de señalar mi propia satisfacción, pues una vez pasadas las primeras sesiones y la inquietud e incertidumbre sobre cómo se desarrollarían y si sería capaz o no de mantener un nivel alto de atención, pude comprobar para mi grata sorpresa, que la participación de los alumnos asistentes fue incrementándose progresivamente, no solo en cuanto a la libre formulación de opiniones sino en relación al nivel de aprendizaje que demostraban adquirir, teniendo que reconocer que yo mismo estaba deseoso de que llegara la siguiente sesión por lo bien que me lo he estado pasando en clase, disfrutando como hacía años que no lo hacía. 
Un hecho a destacar, es que a pesar de que cada sesión duraba dos horas y en contra de mi parecer inicial, creía que me iba a sobrar tiempo en cada una de ellas, porque como decía anteriormente, en un principio pensé que tanto mi capacidad, como la participación de los alumnos iba a ser escasa, la propia dinámica de la clase me obligó casi desde el principio a postponer el Kahoot modelo "Quiz" al comienzo de la siguiente sesión de trabajo, lo que supuso un verdadero acierto, ya que servía a los alumnos de repaso e integración de los conocimientos de la sesión anterior con la del día en cuestión.

En relación a las dificultades encontradas, destacaría particularmente dos, la primera se refiere al hecho de que en el modelo clásico de clase magistral, exponía a los alumnos las imágenes referentes al tema a tratar en un "Powerpoint" y aunque los alumnos disponen de las mismas en los citados "apuntes", que tienen a disposición en la página web de la asignatura, no siempre eran de suficiente calidad al ser estas de menor formato. He de señalar en cualquier caso que para paliar dicho inconveniente, asiduamente llevé a clase modelos reales relacionados con los temas a tratar, algunos de los cuales habían sido objeto de "Ayudas de innovación docente" de cursos anteriores (distintos tipos de prótesis, articuladores semiajustables y arcos faciales, estructuras coladas, utillaje para el procesado de prótesis etc.), además si así se requería para aclarar alguna duda, opcionalmente proyectaba en pantalla alguna de las imágenes de los citados "Powerpoint", con todo ello, según el parecer de los alumnos no ha sido suficiente.

Sin duda la mayor dificultad encontrada, como ya he referido con anterioridad, ha sido el conseguir la asistencia a clase teórica, ya que por los motivos anteriormente mencionados fue muy variable de unas sesiones a otras y además decreciendo a medida que se aproximaban las fechas de los exámenes finales. 
Aun no considerándola una dificultad insalvable, he de mencionar que dada la rigidez del calendario académico impuesto por la Universidad, la duración teórica del CMD, de acuerdo a las normas del ICE, no coincide con la duración temporal de la asignatura, hasta tal punto, que el presente CMD se inició al principio de la asignatura y no como consta en el cronograma propuesto, ya que entendí que según las normas establecidas el CMD debía aplicarse a la asignatura completa y no a parte de ella (de ahí que el apartado de "Secuencias de actividades" emplee el tiempo pasado o futuro para describirlas, ya que alguna de las mismas ya se habían realizado antes del teórico comienzo del CMD).

\section{Evaluación del aprendizaje de los alumnos}

Dada la complejidad de todo proceso de evaluación, he optado por realizar distintos procedimientos.

En primer lugar a través de la propia aplicación del Kahoot en su modelo "Quiz", en las diez sesiones realizadas pude obtener la información que se recoge en la tabla 1, junto a la puntuación media obtenida en cada una de ellas.

TABLA 1

Resultado de la información suministrada con el total de gamificaciones realizadas con el modelo "Kahoot Quiz".

\begin{tabular}{|l|l|}
\hline Información recogida & Puntuación media \\
\hline $\begin{array}{l}\text { Porcentaje de respuestas correctas de los alumnos } \\
\text { del total de "Kahoot" (100 preguntas totales) }\end{array}$ & $88,11 \%$ \\
\hline $\begin{array}{l}\text { Porcentaje de respuestas incorrectas de los alum- } \\
\text { nos del total de "Kahoot" (100 preguntas totales) }\end{array}$ & $11,88 \%$ \\
\hline $\begin{array}{l}\text { Grado de "diversión del alumno" con "La } \\
\text { gamificación" }\end{array}$ & 4,72 (sobre 5 puntos) \\
\hline $\begin{array}{l}\text { Grado de "aprendizaje subjetivo del alumno" con } \\
\text { "La gamificación" }\end{array}$ & $98,61 \%$ \\
\hline
\end{tabular}

Jornadas de Formación e Innovación Docente del Profesorado | № 1 (2018) Esta obra se distribuye con la licencia Creative Commons 


\begin{tabular}{|l|l|}
\hline ¿Recomendaría el alumno este sistema? & $98,61 \%$ \\
\hline $\begin{array}{l}\text { Sensación de satisfacción del alumno tras las } \\
\text { sesiones }\end{array}$ & $84,33 \%$ (sobre 100) \\
\hline $\begin{array}{l}\text { No promedio de alumnos participantes en las } \\
\text { sesiones }\end{array}$ & 19,9 \\
\hline
\end{tabular}

Un segundo proceso de evaluación se realizó a través de un cuestionario de satisfacción que se pasó a los alumnos en la última sesión, (aunque hay que señalar que su valor es relativo dada la escasa asistencia de tan solo 6 alumnos), cuyos resultados podemos consultar en la tabla 2

\section{TABLA 2}

Resultados del cuestionario de satisfacción de los alumnos

\begin{tabular}{|l|l|}
\hline Pregunta del cuestionario & $\begin{array}{l}\text { Puntuación media } \\
0 \text { a } 5 \text { puntos }\end{array}$ \\
\hline $\begin{array}{l}\text { ¿Qué puntuación le pondrías al estilo de clase habi- } \\
\text { tual que te imparten en otras asignaturas? }\end{array}$ & 3 \\
\hline $\begin{array}{l}\text { ¿Qué puntuación le pondrías al estilo de clase interac- } \\
\text { tiva que hemos seguido en la asignatura de prótesis? }\end{array}$ & 4 \\
\hline $\begin{array}{l}\text { Evalúa lo que crees que has aprendido en la Clase ha- } \\
\text { bitual en otras asignaturas }\end{array}$ & 3,5 \\
\hline $\begin{array}{l}\text { Evalúa lo que crees que has aprendido en la Clase In- } \\
\text { teractiva que hemos seguido en la asignatura de } \\
\text { prótesis }\end{array}$ & 4,33 \\
\hline $\begin{array}{l}\text { Aunque a final de curso tuvieras la máxima califica- } \\
\text { ción, si pudieras elegir, ¿qué tipo de clase de las dos te } \\
\text { gustaría tener? }\end{array}$ & $\begin{array}{l}83,33 \% \\
\text { Clase interactiva }\end{array}$ \\
\hline $\begin{array}{l}\text { ¿Cuál de las dos clases te ha resultado más amena? } \\
\text { Clase interactiva }\end{array}$ \\
\hline $\begin{array}{l}\text { ¿En cuál de las dos clases has tenido que trabajar } \\
\text { más? }\end{array}$ & $\begin{array}{l}100 \% \\
\text { Clase interactiva }\end{array}$ \\
\hline
\end{tabular}

Sería bueno aclarar que en la pregunta 5 todos eligieron el tipo de clase interactiva, menos un alumno que optaba por una combinación de ambas. 
El tercer procedimiento se llevó a cabo comparando el cuestionario inicial con el final, para establecer la evolución de las "Escaleras de aprendizaje", no obstante, nos encontramos con el mismo problema anterior, es decir, mientras el cuestionario inicial fue realizado por 23 alumnos, el final tan solo por 6 de los cuales uno no había hecho el cuestionario inicial, con lo que su valor es muy relativo. En cualquier caso trataremos de aportar alguna información.

En la tabla 3 se recoge de manera promedio en cuál de los 5 escalones ( 0 a 4 ) se encontraban los alumnos en relación a las preguntas problemas generales en el cuestionario inicial (23 alumnos)

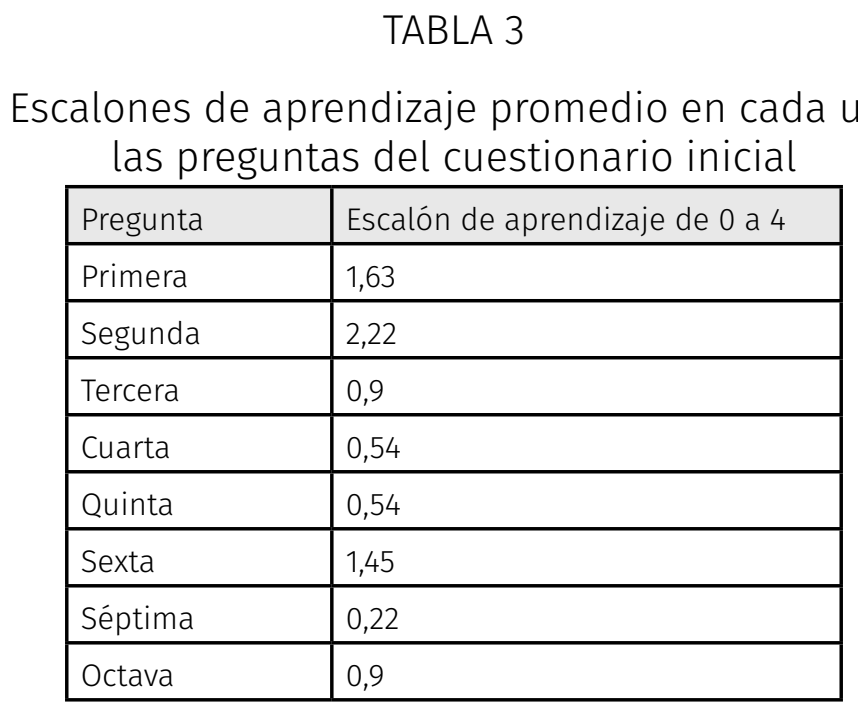

En la tabla 4 recogemos la evolución de los escalones de aprendizaje de los seis alumnos que contestaron el cuestionario final.

Jornadas de Formación e Innovación Docente del Profesorado | № 1 (2018) Esta obra se distribuye con la licencia Creative Commons 
TABLA 4

Evolución de los escalones de aprendizaje de los seis alumnos que completaron el cuestionario inicial-final

\begin{tabular}{|l|l|l|l|l|l|l|l|l|l|l|l|l|l|l|}
\hline Pregunta & \multicolumn{2}{|l|}{ Alumno } & \multicolumn{2}{l|}{ Alumno 2 } & \multicolumn{2}{l|}{ Alumno 3 } & \multicolumn{2}{l|}{ Alumno 4 } & \multicolumn{2}{l|}{ Alumno 5 } & \multicolumn{2}{l|}{ Alumno 6 } \\
\hline & inicial & final & inicial & final & inicial & final & inicial & final & inicial & final & inicial & final \\
\hline Primera & 0 & 0 & 4 & 4 & 0 & 3 & 0 & 0 & 4 & 4 & & 4 \\
\hline Segunda & 3 & 0 & 3 & 4 & 2 & 4 & 2 & 4 & 3 & 3 & & 4 \\
\hline Tercera & 0 & 3 & 1 & 3 & 1 & 1 & 1 & 1 & 0 & 3 & & 3 \\
\hline Cuarta & 2 & 4 & 0 & 0 & 0 & 3 & 2 & 2 & 0 & 4 & & 4 \\
\hline Quinta & 0 & 4 & 0 & 4 & 0 & 3 & 0 & 0 & 0 & 4 & & 4 \\
\hline Sexta & 2 & 4 & 2 & 4 & 2 & 4 & 3 & 4 & 2 & 4 & & 2 \\
\hline Séptima & 0 & 4 & 0 & 3 & 0 & 4 & 0 & 4 & 1 & 4 & & 4 \\
\hline Octava & 0 & 0 & 0 & 0 & 0 & 3 & 3 & 3 & 2 & 3 & & 4 \\
\hline Promedio & 0,87 & 2,37 & 1,25 & 2,75 & 0,62 & 3,12 & 1,37 & 2,25 & 1,5 & 3,37 & & 3,62 \\
\hline
\end{tabular}

Por último, procedimos a comprobar la calificación final obtenida en el examen teórico y práctico final de la asignatura por los alumnos que habían asistido a las sesiones de trabajo, tomando como referencia los 23 alumnos que habían realizado el cuestionario inicial y por otra parte los seis que realizaron el final, comparada con la de aquellos alumnos que no asistieron a ninguna sesión.

\section{TABLA 5}

Calificación teórico-práctica comparada de los alumnos que participaron en el cuestionario inicial y en el inicial-final con respecto a los alumnos que no lo hicieron así como el número de No presentados (NP) en cada uno de los grupos

\begin{tabular}{|l|l|l|l|}
\hline Calificación & Curso Completo & 23 alumnos & 6 alumnos \\
\hline Teoría & $5,1314 \mathrm{NP}$ & $6,512 \mathrm{NP}$ & $6,700 \mathrm{NP}$ \\
\hline Prácticas & 8,23 & 8,17 & 8,33 \\
\hline
\end{tabular}




\section{Evaluación del CMD puesto en práctica}

\section{Cuestiones a mantener y cambios a introducir}

Las cuestiones a mantener son todas las referentes al desarrollo de las sesiones de trabajo, es decir, la estructura de la clase y la incorporación de la gamificación como instrumento de aprendizaje, incluido el hecho de incorporar el Kahoot modelo "Quiz" en la sesión siguiente, por los buenos resultados obtenidos.

Los cambios a introducir se relacionan con las dos dificultades encontradas.

Para soslayar el inconveniente relativo a la falta de visionado en clase de las imágenes de los Powerpoint, en el próximo curso, además de incorporar los "Apuntes de clase con las imágenes en formato pequeño", pondremos a disposición del alumno en formato PDF, las presentaciones del Powerpoint a mayor escala, para que sirvan de ilustración a los citados apuntes.

En relación a incrementar la asistencia de los alumnos a la docencia teórica, me propongo incorporar en el Programa de la asignatura dos tipos distintos de evaluación, uno de ellos, el clásico de examen teórico final, para aquellos alumnos que no deseen asistir y participar en el CMD, el otro dirigido a los alumnos participantes, en el que el los alumnos participantes podrían obtener hasta 5 puntos de la calificación teórico final (que se sumaría a la calificación obtenida en el examen teórico final), estos 5 puntos se obtendrían de la siguiente forma:

- 1 punto por asistencia a todas las sesiones teóricas o con 1 falta

- 0,5 puntos por asistencia a todas las sesiones menos 2

- 0 si tuvieran más de dos faltas excluyéndolos del CMD 
De 0,1 a 1 punto en función de los 10 alumnos que obtuvieran la mayor puntuación en los Kahoot modelo Quiz (1 punto el de mayor puntuación, 0,9 el segundo y así sucesivamente)

Hasta 3 puntos en la resolución de casos problema correspondiente a los tres bloques temáticos que los alumnos trabajarían por grupos, En cada caso problema se plantearían 10 preguntas que los alumnos deben contestar y que serían calificadas con 1 punto si es correcta y completa, 0,5 puntos correcta pero incompleta y 0 puntos incorrecta. Esta evaluación sería hecha por el profesor y supondría el $60 \%$ de los tres puntos referidos, el restante $40 \%$ se obtendría de la evaluación por pares de los propios alumnos dentro de cada grupo.

Por otra parte se incorporarán clases de "Repaso" al final de cada uno de los bloques temáticos para intentar compendiar todo lo aprendido en las clases anteriores y debatir el resultado de los casos problema. Dichas clases seguirían una dinámida similar a la planteada en el resto de las clases, es decir la gamificación como herramienta de estímulo y orientación en el proceso de aprendizaje de los alumnos.

Por último, aunque no depende de mi persona, solicitaría la adecuación de los plazos para el desarrollo del CMD con el calendario de actividades docentes de la Universidad.

Los principios didácticos que deben guiar el futuro se basan en el cambio de paradigma de la figura del Profesor como transmisor del conocimiento en un facilitador y orientador del proceso individual de aprendizaje del alumno, de manera qye genere en el mismo una actitud autocrítica que le permita seguir aprendiendo a lo largo de toda su vida. 


\section{Referencias Bibliográficas}

Bain, K. (2004). Lo que hacen los mejores profesores universitarios. Valencia: Publicaciones Universidad de Valencia.

Cox KR, Ewan CE.(1982). La docencia en Medicina. Barcelona. Doyma.

Porlán, R. (2017). Enseñanza Universitaria, Cómo mejorarla. Madrid: Editorial Morata. 